\title{
Habitat connectivity shapes urban arthropod communities: the key role of green roofs
}

\author{
S. BraAker,,${ }^{1,2,3,4}$ J. Ghazoul,${ }^{2}$ M. K. Obrist, ${ }^{1}$ And M. Moretti ${ }^{3}$ \\ ${ }^{1}$ Swiss Federal Research Institute WSL, Biodiversity and Conservation Biology, Birmensdorf, Switzerland \\ ${ }^{2}$ Institute of Terrestrial Ecosystems, Ecosystem Management, ETH Zurich, Switzerland \\ ${ }^{3}$ Swiss Federal Research Institute WSL, Community Ecology, Bellinzona, Switzerland
}

\begin{abstract}
The installation of green roofs, defined here as rooftops with a shallow soil cover and extensive vegetation, has been proposed as a possible measure to mitigate the loss of green space caused by the steady growth of cities. However, the effectiveness of green roofs in supporting arthropod communities, and the extent to which they facilitate connectivity of these communities within the urban environment is currently largely unknown. We investigated the variation of species community composition ( $\beta$ diversity) of four arthropod groups with contrasting mobility (Carabidae, Araneae, Curculionidae, and Apidae) on 40 green roofs and 40 extensively managed green sites on the ground in the city of Zurich, Switzerland. With redundancy analysis and variation partitioning, we (1) disentangled the relative importance of local environmental conditions, the surrounding land cover composition, and habitat connectivity on species community composition, (2) searched for specific spatial scales of habitat connectivity for the different arthropod groups, and (3) discussed the ecological and functional value of green roofs in cities. Our study revealed that on green roofs community composition of high-mobility arthropod groups (bees and weevils) were mainly shaped by habitat connectivity, while low-mobility arthropod groups (carabids and spiders) were more influenced by local environmental conditions. A similar but less pronounced pattern was found for ground communities. The high importance of habitat connectivity in shaping high-mobility species community composition indicates that these green roof communities are substantially connected by the frequent exchange of individuals among surrounding green roofs. On the other hand, low-mobility species communities on green roofs are more likely connected to ground sites than to other green roofs. The integration of green roofs in urban spatial planning strategies has great potential to enable higher connectivity among green spaces, so that eventually even communities of low-mobility species become connected. Furthermore, improving the design of green roofs (composition and configuration of vegetation and soil types) could enhance the ecological value, particularly for low-mobility species.
\end{abstract}

Key words: bees; brownfield; city; fragmentation; ground beetles; living roof; Moran eigenvector maps, MEM; spatial analysis; spiders; urban; weevils.

\section{INTRODUCTION}

Since 2008, more than $50 \%$ of the global human population and almost $80 \%$ of the population in developed countries lives in cities (United Nations 2012). Increasing urban populations lead to urban sprawl, but also to further development of urban centers (Dallimer et al. 2011) with consequent loss of green spaces, causing strong alterations of ecosystem processes and trophic interactions (Pickett et al. 2001, Grimm et al. 2008). Yet urban green areas have been shown to support native biodiversity (McIntyre et al. 2001, Sattler et al. 2011), enhance ecosystem functions (Alberti 2005, Hennig and Ghazoul 2011), provide important ecosys-

Manuscript received 15 April 2013; revised 6 August 2013; accepted 13 August 2013; final version received 7 September 2013. Corresponding Editor: M. Eubanks.

${ }^{4}$ E-mail: sbraaker@gmx.net tem services (Tratalos et al. 2007), and contribute to human well-being (Fuller et al. 2007). Consequently, they can provide various environmental, economic, or social benefits, even though they are often designed for a single purpose only.

In the urban ecosystem, extensively managed green areas in the form of road verges, waste land, gravel pits, and dry meadows are characterized by dry microclimate, shallow or nutrient-poor substrates, and/or frequent disturbances. Rural habitats with similar characters such as riverbanks, sand pits, areas cleared by wind, avalanches, or fire, and dry grassland have declined throughout Europe during the last decades under the pressure of agricultural and forestry intensification and urbanization. As a consequence, many species adapted to these particular habitats have become rare or even threatened (Thomas et al. 1994, Lundholm and Richardson 2010, Wesche et al. 2012). These urban, extensively managed, green areas are often rich in 
ruderal or stress-tolerant plant species (sensu Grime 1977) and can act as refuges for some species, both fauna and flora, that have declined in extensively managed, rural, green areas (Maurer et al. 2000, Öckinger et al. 2009a). To counteract the loss of green space in cities, green roofs, defined as rooftops with a shallow soil cover and extensive vegetation, have recently been widely promoted (Gedge and Kadas 2005, Brenneisen 2006, Francis and Lorimer 2011). The ecosystem functions and services of green roofs related to biogeochemical cycles have been well investigated (e.g., Oberndorfer et al. 2007, Berndtsson 2010), while only a few studies have focused on the potential of green roofs as habitat for biodiversity (Brenneisen 2006, Olly et al. 2011, Tonietto et al. 2011). Nonetheless, it is currently unknown what processes shape arthropod assemblages on green roofs, whether green roof communities are connected to each other and with habitats on the ground level and, hence, whether green roofs function as stepping stones (Francis and Lorimer 2011). Understanding the mechanisms that explain species' distributions in urban ecosystems is essential for the development of efficient strategies to enhance the ecological and functional value of urban habitats.

Leibold et al. (2004) defined four distinct paradigms for metacommunity theory, of which two describe the mechanism of community assembly ( $\beta$ diversity) in environmentally heterogeneous habitat patches that are relevant to our study. The species-sorting paradigm predicts that community composition is mainly influenced by niche processes (local environmental conditions and species interactions) while the mass-effect paradigm assumes that dispersal processes (immigration and emigration) shape community assemblages principally. These two paradigms are not mutually exclusive; rather, they can both shape the community composition to varying degrees depending on the characteristics of the species within the investigated community (Logue et al. 2011).

The quantification of successful dispersal of organisms in empirical studies is very difficult and costly, thus empirical habitat connectivity models investigating connectivity in relation to biotic dispersal processes are usually based on the observation of few individuals, which limits the generalization of the results. An alternative approach is to assess the response of species community composition to habitat connectivity. Community composition at a given site is defined in this study as the ensemble of species sampled with their abundance ( $\beta$ diversity, species by sites matrix with abundances). Habitat connectivity for a given community depends on the resource requirements (e.g., habitat and food) and the mobility of the species that the community is composed of (With et al. 1997, Baguette and Van Dyck 2007). The term "mobility" comprises two subordinates (Van Dyck and Baguette 2005), (1) routine movement performed to access daily resources (e.g., foraging), and (2) dispersal movement (e.g., movement from a natal/breeding site to another breeding site). Since both movement types can be relevant, especially in fragmented landscapes, the term mobility will be used for both routine and dispersal movement together (Van Dyck and Baguette 2005). Resource requirements and mobility must be taken into account for the determination of the appropriate scale, called scale of effect, at which community composition is best predicted by environmental variables such as habitat connectivity or surrounding land cover (Jackson and Fahrig 2012). Communities dominated by species with low mobility are expected to respond to smaller scales of effect than species with high mobility (Baguette and Van Dyck 2007, Öckinger et al. 2009b). Further, species moving randomly or passively are predicted to respond to smaller scales than species whose movement depends on biotic (e.g., social cues), or abiotic cues (e.g., landmarks) referred to as uninformed and informed movement, respectively (Clobert et al. 2009, Jackson and Fahrig 2012).

In our study, we investigated how local and dispersal processes affected variation in arthropod community composition ( $\beta$ diversity, species by sites matrix with abundances) among 40 green roofs and 40 ground sites in the central European city of Zurich, Switzerland. To identify the relative importance of these two processes, we measured local environmental conditions at the sampling site (local processes) the composition of the surrounding land cover (both local and dispersal processes, depending on the scale), and habitat connectivity (dispersal processes); See Fig. 1. We investigated variation in arthropod communities for four arthropod groups with contrasting resource requirements and mobility: carabid beetles (Carabidae); spiders (Araneae); weevils (Curculionidae), and bees (Apidae). In particular, we sought to answer the following three questions: (1) What is the relative importance of the local environment, the surrounding land cover, and habitat connectivity for urban arthropod communities with contrasting mobility? (2) How do spatial scales of habitat connectivity differ among arthropod groups? (3) What is the ecological and functional value of green roofs in an urban landscape?

\section{Methods \\ Sampling sites}

The study was conducted in Zurich, located on a lake in the Swiss central plateau in the center of the Zurich Metropolitan Area, which has 1.9 million inhabitants according to the 2012 census. It contains densely builtup residential and industrial areas, but also a large number of historic, new public, and private green spaces (Hennig and Ghazoul 2011). A considerable number of buildings also support rooftops with intensively or extensively managed vegetation ( 87 ha of vegetated roofs in 2007 [Tschander 2007]). We selected 40 extensively managed green roofs with a gradient of vegetation composition, from pure Sedum to ruderal 
and dry meadow vegetation. In addition, we selected 40 extensively managed green sites on the ground with the best possible analogue to roof vegetation, ranging from ruderal vegetation to dry meadows. Two ground sites could not be used for analyses due to equipment vandalism. The sampling sites were distributed over the entire city (Fig. 2, bottom right) with a median distance between two nearest sampling sites of $242 \mathrm{~m}$ $(25 \%$ quartile $=109 \mathrm{~m} ; 75 \%$ quartile $=479 \mathrm{~m}$.

\section{Arthropod data}

At each site, surface-dwelling arthropods were sampled using six pitfall traps (72 $\mathrm{mm}$ in diameter, covered with transparent roofs $10 \mathrm{~cm}$ above as rain protection) arranged in isosceles triangles with a side length of $1 \mathrm{~m}$, and with a minimum of $20 \mathrm{~m}$ distance between triplets. Air-dispersing arthropods were captured using a nondirectional trap that combined a window interception trap with a yellow pan trap (diameter $44 \mathrm{~cm}$ ) placed $1.5 \mathrm{~m}$ above ground (Duelli et al. 1999). Both trap types were filled with a $0.2 \%$ Rocima solution (a bactericidefungicide from Acima, Buchs, Switzerland) and were emptied on a weekly basis between 24 May 2010 and 3 September 2010. Four arthropod groups with different routine and dispersal movement distances, and with distinct movement behavior (informed and uninformed movement), were identified to the species level by specialists (see Acknowledgements). Ground beetles (Carabidae, hereafter carabids) are ground-dwelling beetles that are mainly aerial dispersers in open habitats (Riecken and Raths 1996). Spiders (Araneae) are also ground dwelling, showing web-building sedentary, or cursorial (hunters by pursuing) behavior (Uetz et al. 1999). Many species are able to perform passive, uncontrolled, aerial dispersal by ballooning (Bell et al. 2005). Weevil species (Curculionidae) in open habitats are reasonably good fliers, able to perform long-distance dispersal, and are known to react to pheromones or plant cues (Solbreck 1980, Francke and Dettner 2005). Bees are good fliers, sometimes disperse long distances, and rely on biotic and abiotic cues (Biesmeijer and Slaa 2004, Zurbuchen et al. 2010). Although we recognize that mobility at the species level within these four taxonomic groups varies, we assume variation in mobility within arthropod communities to be smaller than between communities. We distinguished between low-mobility community groups (carabids and spiders) and high-mobility community groups (weevils and bees) based on the above-mentioned mobility and the ability to use cues for movement. Honey bees (Apis mellifera) were excluded from the analysis since they are dependent on the location of apiaries and are thus likely to show different responses to wild bees. To investigate potential differences in response between communities on roof and ground sites, we conducted separate analyses for three community types for each arthropod group, respectively (carabids, spiders, weevils, and bees): (1) roof communities, made up of roof sites only (roof); (2) ground communities, made up of ground sites only (ground); and (3) the combination of roof and ground communities, all sites (roof + ground), to have a further indication of connectivity between roof and ground communities. This resulted in a total of 12 species by sites matrices with abundances, subsequently referred to as arthropod communities.

\section{Environmental variables}

We measured three sets of environmental variables (Table 1) related to local and dispersal processes expected to affect arthropod community composition ( $\beta$ diversity, species by sites matrix with abundances). The first variable set comprised six local variables that we predicted to be related to niche processes, describing the age of the vegetation (age), the size of the sampling site (size), the proportion of bare ground (bare ground), the proportion of forbs (forbs), the number of plant species (plants), and flower abundance (flowers). Flower units were counted in a $3-\mathrm{m}^{2}$ area, with a stratified distribution at each site every second week. Densely clustered floral heads such as Apiaceae, Asteraceae, and Fabaceae were counted as a single flower unit. Flower abundance per site was averaged across the whole sampling period.

For the second variable set, we quantified the proportion of six different land cover types (buildings, impervious areas [impervious], woody plants [wood], urban extensively managed green areas [extensive green], homogeneous green, and structured green) at four spatial scales $(100,200,300$, and $400 \mathrm{~m}$ radii) around our sampling sites (Table 1). In order to exclude the spatial overlap between the local and the land cover variable set a priori, which would influence the intended variation partitioning analyses, the area in a radius of 50 $\mathrm{m}$ around the sampling sites was excluded from the 100$400 \mathrm{~m}$ radii. We retrieved land cover types from a GIS habitat map of Zurich at the level of individual lots with a precision of $\pm 10 \mathrm{~m}$ (Biotoptypenkartierung der Stadt Zürich 2010), in combination with GIS layers of buildings and streets from the Swiss Federal Office of Topography (Vector25 Swisstopo 2011). To be sure that the scale was arthropod community specific, we performed redundancy analyses (Baranyi et al. 2011) with each arthropod community (as multivariate response) and land cover type at different radii (as univariate predictor) and selected only the raduis, resulting in highest adjusted $R^{2}, R_{\text {adj }}^{2}$ (Peres-Neto et al. 2006).

The third variable set, called connectivity, consisted of two subsets: landscape configuration and spatial patterns. For the first subset, we used three landscape configuration metrics (McGarigal et al. 2012, Rempel et al. 2012): edge density (edge), mean proximity (proximity), and mean nearest neighbor distance (neighbor) at four spatial scales $(100,200,300$, and $400 \mathrm{~m}$ radii) with four distinct binary landscape classifications dividing land cover into either suitable habitat or hostile matrix, subsequently referred to as habitat-matrix classifications 


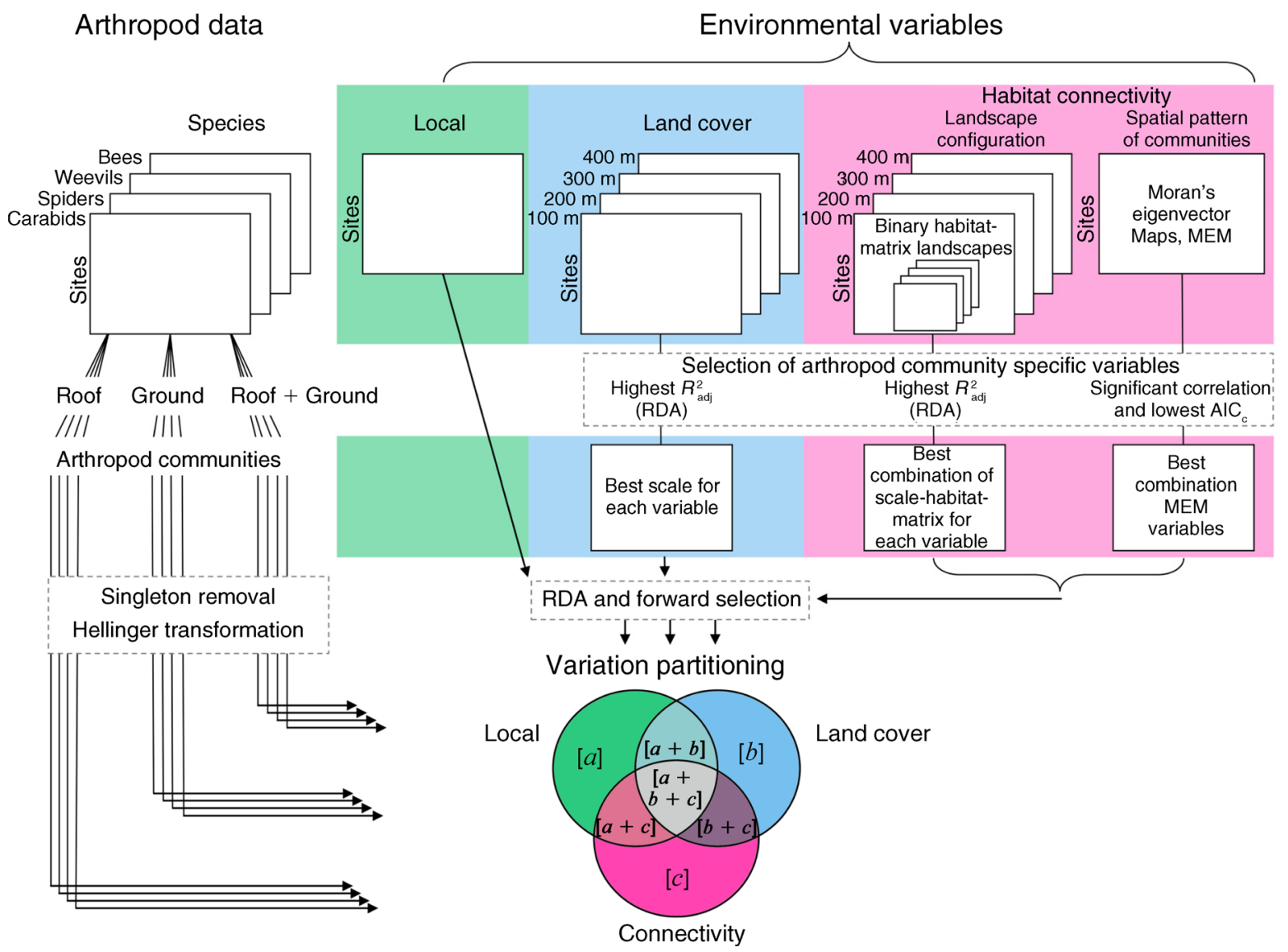

FIG. 1. Overall scheme of the data sets and analyses performed. Four arthropod groups of three community types (Roof, Ground, and Roof + Ground) were analyzed, resulting in a total of 12 analyses. Three variable sets (local, land cover, and habitat connectivity) were used to explain variation in arthropod communities. In the Venn diagram of variation partitioning $[x]$ are pure fractions, $[x+y]$ are joint fractions of the predictor sets according to Fig. 2 and Appendix: Table A2. See Methods for a detailed description of the analyses.

(Table 1). To account for the various mobility and resource requirements of the investigated arthropod communities, we used only the combination of scale with habitat-matrix classification resulting in the highest $R_{\text {adj }}^{2}$ for the respective arthropod community. For the second subset of habitat connectivity, we searched for explanatory variables that describe spatial patterns at different scales for each arthropod community using Moran's eigenvector maps MEM (MEM; Dray et al. 2006). These spatial patterns reflect the habitat connectivity among sites. The MEM method, a generalization of the Principal Coordinates of Neighbor Matrices, PCNM, is based on the eigenvalue decomposition of geographic connectivity matrices among sampling sites. This means that MEM decomposes the spatial relationships into components, called eigenvectors, which represent the variation at specific spatial scales. Eigenvectors, or principal coordinate axes, resulting from the connectivity matrices reflect the decompositions of Moran's $I$ statistic into all mutually orthogonal maps that can be generated from a given connectivity matrix (Griffith and Peres-Neto 2006). Through a selection process, eigenvectors with significant spatial autocorrelation are chosen, which can then be used as explanatory variables for spatial patterns. Several MEM variables, thus several spatial patterns, can simultaneously describe the community structure in the landscape. We performed the following sequential steps to detect spatial MEM variables as suggested by Borcard et al. (2011): (1) the definition of a neighborhood graph (Gabriel graph) of sites as binary connectivity matrix (R-package spdep; Bivand 2011), (2) the construction of MEMs (R-package spacemakeR; Dray 2010), (3) the selection of eigenvectors with positive and negative spatial correlation, and (4) the identification of the model with selected eigenvectors that results in the lowest Akaike information criterion with small sample size correction $\left(\mathrm{AIC}_{\mathrm{c}}\right.$; Burnham and Anderson 2002). For each arthropod community, we mapped the fitted site scores of the final selected eigenvectors to discriminate between large-, medium-, and small-scale spatial patterns (eigenvectors 1-3 are large, 6-10 are medium, and $>15$ are small scale; Borcard et al. 2011). 

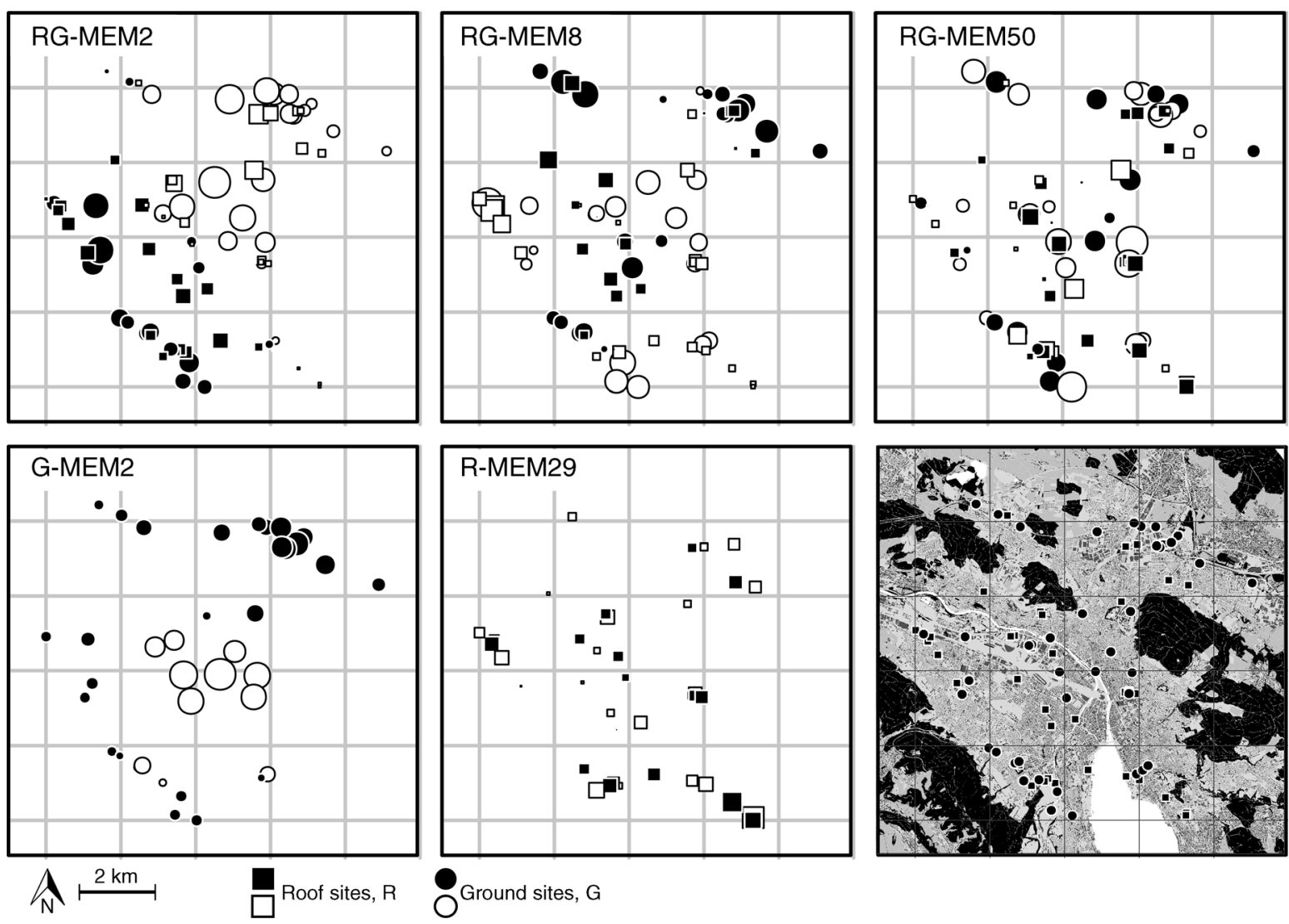

FIG. 2. Moran's eigenvector maps, MEM. Five examples of fitted sampling site scores of selected eigenvectors, MEM variables, are plotted on a geographical coordinate grid. Increasing size of the symbols corresponds to increasing positive values, in black, and increasing negative values, in white, of the eigenvector (Hawkins et al. 2007). Communities with the same color show similarity in species composition, and the size of the symbols indicates the level of similarity; small symbols stand for low similarity, large symbols stand for high similarity. From left to right, the top row shows selected MEM variables for roof + ground (RG) communities of large (RG-MEM2, selected for bees; see Table 2), medium (RG-MEM8, carabids and bees), and small (RGMEM50, carabids) spatial scale. The bottom row shows, from left to right, the large-scale variable for ground (G) communities (GMEM2, weevils and spiders) and the small-scale variable for roof (R) communities (R-MEM29, carabids and spiders). The last square shows a map of Zurich with the sampling sites. Forest is represented in black, lakes and rivers in white, and buildings in dark gray. All other land cover types are in light gray. The prominent straight gray line in the middle of the map represents the main railway track.

\section{Statistical analyses}

To answer the research questions, we performed the three analysis steps (variable selection, redundancy analysis, and variation partitioning) that are illustrated in Fig. 1. All analyses were done separately for the 12 arthropod communities (species by sites matrices with abundances). First, we used a variable-selection process to identify the variables within our three sets of variables (local, land cover, and connectivity) that significantly shape the arthropod communities. We excluded singletons, since the absence of rare species at sites is likely a sample-size effect that might artificially increase the variance of the analyses. The abundance of species was Hellinger-transformed to reduce the effect of extreme values and the effect of double absences in the species by sites matrix (Legendre and Gallagher 2001). To achieve normality of variables, we used arcsine transformation for all variables measured as proportions $(\arcsin \sqrt{p}$, where $p$ is a proportion), $\log _{10}$ transformation for size and flowers, and $\log _{10}(x+1)$ transformation for the variable age. Variables within variable sets with a variance inflation factor (VIF) value $>3$ were iteratively excluded from the analysis to minimize collinearity effects (Zuur et al. 2009). For each variable set, we ran a forward selection with a double stopping criteria that assures a correct Type I error (Blanchet et al. 2008), to identify the variables significantly explaining variation in community composition $(P<0.05$ after 10000 random permutations). Second, we used a constrained canonical ordination method (redundancy analysis, RDA) to explain the variation in community composition. RDA combines multivariate multiple linear regression analysis with principal component analysis to model multivariate response data, in this study, community composition. 
TABLE 1. Environmental variable sets used to assess local and dispersal processes that shape community composition.

\begin{tabular}{|c|c|}
\hline Variable & Description \\
\hline \multicolumn{2}{|l|}{ Local (local processes) } \\
\hline Age & Age of vegetation measured in years since last structural modification. \\
\hline Size & Area in square meters. \\
\hline Bare ground & Proportion covered by bare ground. \\
\hline Forbs & Proportion covered by herbaceous flowering plants, without Crassulaceae. \\
\hline Plants & Number of plant species. \\
\hline Flowers & Mean flower abundance. \\
\hline \multicolumn{2}{|c|}{$\begin{array}{l}\text { Land cover composition as proportions in } 100 \mathrm{~m}, 200 \mathrm{~m} \text {, } \\
300 \mathrm{~m}, 400 \mathrm{~m} \text { radii (local and dispersal processes) }\end{array}$} \\
\hline Buildings & Any kind of building. \\
\hline Impervious & Impervious surfaces (e.g., asphalt roads, parking lots, squares). \\
\hline Wood & Groups of bushes and trees, forest patches. \\
\hline Extensive green & Extensively managed urban green areas (e.g., road verges, waste land). \\
\hline Homogeneous green & Homogeneous urban green without vegetation structures (e.g., lawns, meadows). \\
\hline Structured green & Urban green with vegetation structures (e.g., gardens, parks). \\
\hline \multicolumn{2}{|c|}{ Habitat connectivity (dispersal process) } \\
\hline \multicolumn{2}{|c|}{$\begin{array}{l}\text { Landscape configuration in } 100 \mathrm{~m}, 200 \mathrm{~m}, 300 \mathrm{~m} \text {, and } \\
400 \mathrm{~m} \text { radii measured based on four binary landscape } \\
\text { classifications (habitat-matrix classifications) }\end{array}$} \\
\hline Edge $\uparrow$ & $\begin{array}{l}\text { Edge density is the sum of the lengths of landscape boundaries between habitat and } \\
\text { matrix divided by the total landscape area. }\end{array}$ \\
\hline Proximity $\dagger$ & $\begin{array}{l}\text { Mean proximity is the sum of habitat area divided by the squared nearest distance } \\
\text { (edge to edge) between the habitat and the focal habitat patch, summed across all } \\
\text { habitat patches in the landscape and divided by the total number of habitat } \\
\text { patches. }\end{array}$ \\
\hline Neighbor † & $\begin{array}{l}\text { Mean nearest neighbor distance is the sum of the distance (edge to edge) to the } \\
\text { nearest habitat in the landscape for each habitat patch, divided by the number of } \\
\text { habitat patches. }\end{array}$ \\
\hline \multicolumn{2}{|c|}{$\begin{array}{l}\text { Habitat-matrix classifications used to calculate edge, } \\
\text { proximity, and neighbor }\end{array}$} \\
\hline Brown & Habitat, extensive green and green roofs; matrix, all other land cover types. \\
\hline Urbangreen & Habitat, homogeneous green and structured green; matrix, all other land cover types. \\
\hline Vegetation & $\begin{array}{l}\text { Habitat, extensive green, green roofs, homogeneous, and structured green; matrix, all } \\
\text { other land cover types. }\end{array}$ \\
\hline Nonvertical & Habitat, all land cover types except matrix; matrix, buildings and woody plants. \\
\hline \multicolumn{2}{|c|}{ Spatial patterns of communities } \\
\hline MEM variables & $\begin{array}{l}\text { Significant spatial variables of Moran's eigenvector maps (MEM). MEM variables } \\
\text { describe spatial patterns at large (eigenvectors 1-3), medium (eigenvectors 6-10), } \\
\text { and small (eigenvectors }>15 \text { ) scales. For details, see Methods. }\end{array}$ \\
\hline
\end{tabular}

Notes: Local variables are measured at the scale of the sampling site. The scales for land cover and habitat connectivity variables are selected specifically for each arthropod community.

$\dagger$ Calculated with ArcGis extension Patch Analyst 4 (Rempel et al. 2012) for Fragstats (McGarigal et al. 2012).

Third, we applied variation partitioning to quantify pure and joint contribution of the three groups of independent variables (local, land cover, and connectivity) to model prediction. With this method, only pure fractions can be tested for significance. Variation partitioning has previously been used successfully to disentangle the impact of local and spatial processes on variation in community composition (Legendre et al. 2005). We applied RDA and variation partitioning with the $\mathrm{R}$ package vegan (Oksanen et al. 2011), using as explanatory matrices the significant variables grouped into local, land cover, and connectivity variables, and the species by sites matrices with abundances as response. To make the results comparable among analyses, we standardized the variation explained by pure and joint fractions of the three variable sets with the total variance explained. Statistical analyses were performed using R version 2.13.0 (R Development Core Team 2011) unless otherwise stated.

\section{Results}

During an 11-week period from May to September we captured 8676 carabids ( $39 \%$ of specimens on roofs) from 72 sepecies, 26070 spiders (45\% on roofs) from 163 species, 5157 weevils ( $26 \%$ on roofs) from 118 species, and 8181 bees (58\% on roofs) from 126 species. A high proportion of species occurred only on roof sites (e.g., $21 \%$ of spider species) or only on ground sites (e.g., $39 \%$ of bee species) and around $50 \%$ of the sampled species occurred on both roof and ground sites (Appendix: Table A1). The proportion of total individuals caught in window interception traps compared to pitfall traps (carabids, $10 \%$; spiders, $3 \%$; weevils, $64 \%$; bees, $79 \%$ ) was in line with the expected lower mobility of carabids and spiders, and the expected higher mobility of weevils and bees. 
TABLE 2. Environmental variables (Table 1) significantly explaining community compositions.

\begin{tabular}{|c|c|c|c|c|c|c|}
\hline & \multicolumn{4}{|c|}{ Roof } & \multicolumn{2}{|c|}{ Ground } \\
\hline & Carabids & Spiders & Weevils & Bees & Carabids & Spiders \\
\hline \multicolumn{7}{|l|}{ Local } \\
\hline Forbs & $\mathrm{x}$ & $\mathrm{x}$ & & & & \\
\hline Bare ground & $\mathrm{x}$ & $\mathrm{x}$ & & & $\mathrm{x}$ & $\mathrm{x}$ \\
\hline Size & & & & & $\mathrm{x}$ & $\mathrm{x}$ \\
\hline Age & & $\mathrm{x}$ & & & & \\
\hline Plants & & & & & & \\
\hline Flowers & & & & & & \\
\hline \multicolumn{7}{|l|}{ Land cover } \\
\hline Buildings & & 300 & & & 400 & 100 \\
\hline Homogeneous green & & & & 400 & & 200 \\
\hline Structured green & & & & & & \\
\hline Wood & 300 & & 400 & 400 & 400 & 200 \\
\hline \multicolumn{7}{|l|}{ Connectivity } \\
\hline \multicolumn{7}{|c|}{ Landsacape configuration } \\
\hline Edge & & & Brown 400 & & & Vegetation 200 \\
\hline Proximity & Nonvertical 200 & Brown 200 & Vegetation 300 & Vegetation 300 & & Vegetation 200 \\
\hline Neighbor & Vegetation 300 & Nonvertical 400 & & Vegetation 200 & & \\
\hline \multicolumn{7}{|l|}{ Spatial pattern } \\
\hline MEM variables & R 29 & R 29 & $\mathrm{R} 6$ & $\mathrm{R} 9,35$ & & G 2 \\
\hline
\end{tabular}

Notes: Selected local variables are indicated by x's. For the selected land cover variables, the radius scale is indicated (in meters). Connectivity variables are divided into landscape configuration and spatial patterns. For the selected landscape configuration metrics, the habitat-matrix classification (Table 1) followed by the scale is shown. Spatial patterns of communities are described by selected MEM variables for roof, ground, and roof + ground communities; see Methods. Cells are empty if no variables have been selected; e.g., roof communities of carabids were significantly shaped by forbs, bare ground, wood in 300 m radius, the connectivity variables proximity calculated with nonvertical in $200 \mathrm{~m}$ radius, neighbor with vegetation in $300 \mathrm{~m}$ radius and by the spatial small scale pattern MEM R29.

\section{Variables affecting roof and ground arthropod communities}

Table 2 summarizes the environmental variables that significantly explain variation in arthropod species composition of each taxa for roof, ground, and roof + ground communities.

Roof communities.-Carabid and spider communities were both influenced by the proportion of forbs and bare ground, while age was significant for spiders only (Table 2). Bare ground shaped weevil assemblages, whereas none of the local variables affected bee communities on roofs. Only a few variables of the surrounding land cover had an effect on roof communities, with the proportion of wood being the most frequently selected variable. Both the landscape configuration metrics proximity and neighbor and the spatial community patterns (MEM variables) were frequently selected connectivity variables. The spatial scale related to MEM variables of roof communities was larger (i.e., small MEM scores) for weevils and bees, as expected from their higher mobility (see selected MEM variables mapped in Fig. 2).

Ground communities.-All ground communities were shaped by the local variables bare ground and size and by the land cover variables buildings and wood (Table 2). Additionally, for bees, the proportion of homogeneous green and structured green were significant. Only carabid communities were not shaped by connectivity at all, while spiders and weevils were affected by landscape configuration metrics edge and proximity. For bees, only the connectivity variables edge and neighbor were significant.

Roof + ground communities.-Forbs, bare ground, and size were the main local variables that shaped roof + ground communities, while age only played a role for spiders and plants only for weevils (Table 2). The proportion of buildings and wood affected all arthropod groups with increasing scales according to the mobility of the group (carabids, $100 \mathrm{~m}$ radius; bees, $400 \mathrm{~m}$ radius), whereas homogeneous green and structured green were only significant for bees. The landscape configuration metric edge, calculated with habitatmatrix classification using non-vertical land cover as habitat, was important for all arthropods; proximity only affected spiders and weevils, while neighbor was significant for carabids, spiders, and bees. Significant spatial community patterns, MEMs, were detected, with the spatial scale increasing with higher mobility of the arthropod group. Most importantly, mapping of selected MEM variables showed a clustering of roof and ground communities that indicates a similarity and thus connectivity between nearby roof and ground sites (Fig. 2).

\section{Relative importance of connectivity compared to local and land cover variables}

All environmental variable sets together explained between $8 \%$ (weevils on roofs) and $26.2 \%$ (spiders on 
TABLE 2. Extended.

\begin{tabular}{|c|c|c|c|c|c|}
\hline \multicolumn{2}{|c|}{ Ground } & \multicolumn{4}{|c|}{ Roof + ground } \\
\hline Weevils & Bees & Carabids & Spiders & Weevils & Bees \\
\hline \multirow{4}{*}{$\begin{array}{l}\mathrm{x} \\
\mathrm{x}\end{array}$} & & $\mathrm{x}$ & $\mathrm{x}$ & $\mathrm{x}$ & $\mathrm{x}$ \\
\hline & $\mathrm{x}$ & $\mathrm{x}$ & $\mathrm{x}$ & $\mathrm{x}$ & $\mathrm{x}$ \\
\hline & $\mathrm{x}$ & & $\mathrm{x}$ & $\mathrm{x}$ & $\mathrm{x}$ \\
\hline & & & $\mathrm{X}$ & $\mathrm{x}$ & \\
\hline \multirow[t]{3}{*}{300} & 100 & 100 & 100 & 400 & 400 \\
\hline & 300 & & & & 300 \\
\hline & 100 & & & & 100 \\
\hline 200 & 200 & 100 & 200 & 200 & 400 \\
\hline \multirow{2}{*}{$\begin{array}{l}\text { Nonvertical } 200 \\
\text { Vegetation } 200\end{array}$} & Nonvertical 400 & Nonvertical 100 & Nonvertical 200 & Nonvertical 100 & Nonvertical 400 \\
\hline & Urbangreen 200 & Brown 200 & $\begin{array}{l}\text { Vegetation } 200 \\
\text { Brown } 100\end{array}$ & Vegetation 200 & Urbangreen 200 \\
\hline G 2 & & RG $8,16,50$ & RG 10 & RG 6 & RG $2,3,8$ \\
\hline
\end{tabular}

ground sites) of variance in community composition (Appendix: Table A2). The relatively low total variance explained, which is nevertheless comparable to other urban studies (Sattler et al. 2010, Bates et al. 2011), is likely the consequence of the heterogeneous landscape of cities and potentially of some unmeasured variables. The maximal difference in total variance explained of roof, ground, and roof + ground communities for the same arthropod group ranged between $0.99 \%$ for bees to $6.29 \%$ for carabids.

Roof communities.-Local variables explained a large proportion of relative variance in the community composition of carabids and spiders (40-50\%; Fig. 3), while they were not relevant for bees and weevils. Pure land cover fractions were small for all arthropods and there were no joint fractions with local variables. For carabids and spiders, connectivity fractions contributed to $30-50 \%$ of the total variance. For weevils and bees, connectivity was by far the most important variable $(>80 \%)$. The pure connectivity fraction for weevils and bees was very high (40-70\%). In general, the importance of connectivity was higher and consequently the importance of local variables was lower for weevil and bee communities compared to carabid and spider communities.

Ground communities.-Pure local fractions were relevant and significant for spiders and carabids only (1743\%; Fig. 3, Appendix: Table A2 for significance of pure fractions), in contrast to pure and joint fractions of land cover, which were relatively large $(30-60 \%)$ for all arthropods. Land cover fractions were similarly high for carabids, spiders, and bees $(60 \%)$ and smaller only for weevils (30\%). Connectivity did not explain any variance for carabids, while pure connectivity fractions were significant for weevils and joint connectivity fractions accounted for a large part of variance explained for spiders, weevils, and bees (40-50\%). The importance of connectivity fractions was higher and the importance of local fractions was lower for weevils and bees than for carabids and spiders, which is consistent with the pattern detected in roof communities.

Roof + ground communities.-Almost no variation across mobility groups of arthropods was visible for roof + ground communities (Fig. 3). Local fractions were the most important (30-60\%), while pure land cover fractions were small $(20 \%)$ for all arthropods except for bees. Pure connectivity fractions made up 15$29 \%$ of total variance explained.

\section{DisCUSSION}

\section{Mobility and the importance of local and dispersal processes}

On the 40 green roofs we investigated, we observed a higher relative importance of local processes in shaping low-mobility carabid and spider communities ( $\beta$ diversity; species by sites matrix with abundances) compared to a higher importance of dispersal processes (connectivity) in shaping high-mobility weevil and bee communities. The same pattern was also found for communities on the ground, although less pronounced. This finding is in agreement with our expectation that the importance of local processes in shaping community composition diminishes with increasing mobility and more informed movement of the arthropods. As previously suggested, in natural environments, the clearly delineated theoretic species-sorting and mass-effect paradigms of Leibold et al. (2004) are not mutually exclusive but rather the 
importance of the processes linked to the paradigms are shifting according to the mobility of the species community (Lindstrom and Ostman 2011, Logue et al. 2011). The low influence of dispersal processes on lowmobility carabids and spiders compared to local processes, can be explained by the small spatial scale needed by carabids and spiders to access all required resources. An alternative explanation is that high dispersal costs, such as decreased motivation to move between patches, increased mortality during displacement across hostile habitat, and low probability of effective settlement in new habitats (Baguette and Van Dyck 2007), lead to reduced connectivity for lowmobility communities at the scale we measured. The effect of connectivity on low-mobility communities might be stronger if a finer spatial scale was used, but results based on such a small scale would no longer be relevant for practical implementation. In contrast, highmobility species have lower dispersal costs, and thus benefit from high dispersal rates (Thomas 2000). Especially since bees use social and landmark cues (Biesmeijer and Slaa 2004) and weevils use pheromones (Francke and Dettner 2005) to move through the landscape, their communities may be more strongly shaped by habitat connectivity.

The observed stronger impact of connectivity on roof communities compared to ground communities for all four investigated arthropod groups is likely to be the result of a combination of an environmental filtering effect restricting the colonization of vertically isolated green roofs to species, within arthropod communities, with higher mobility and ability to survive the environmental conditions on roofs, and a generally higher dispersal propensity of individuals living on green roofs (Hanski et al. 2004). The filtering effect is corroborated by the considerable number of species unique to roof sites, most likely originating from habitats outside the city. Further, it leads to communities adapted to the conditions of roof and ground sites, respectively, which might be an explanation for the higher importance of local processes and simultaneously lower importance of dispersal processes for roof + ground communities compared to high-mobility roof and ground communities (Urban 2004).

\section{Spatial scales of habitat connectivity}

In accordance with our expectations, communities of low-mobility species respond to habitat connectivity at smaller spatial scales than most communities of highmobility species. This emphasizes that the scale of effect is strongly linked to the mobility of the species community and must be taken into account when conducting research and implementing management measures that are related to habitat connectivity (Taylor et al. 1993, Baguette and Van Dyck 2007, Jackson and Fahrig 2012). Although spatial distribution patterns from the urban fringe to the urban center have frequently been documented (Weller and Ganzhorn 2004, Ahrne et al. 2009,
Threlfall et al. 2011), we only detected such a community structure for spiders and weevils on the ground $(\mathrm{G}-$ MEM2 in Fig. 2), while for all other investigated communities, the spatial patterns were more complex and not related to an environmental rural-urban gradient. Ramalho and Hobbs (2012) suggested that, in contemporary cities, the mechanisms responsible for species distribution can only be partially captured with the traditional concept of a linear rural-urban gradient. Our results indicate that complex spatial patterns are not only relevant for contemporary but also for historic cities, such as Zurich, that have undergone strong polycentric expansion in recent decades (Schmid 2004).

\section{Ecological and functional value of green roofs}

While the high potential of green roofs to increase habitat for plants and arthropods in cities has been frequently suggested (Brenneisen 2006, Tonietto et al. 2011), the function of green roofs as a connecting element in the urban habitat patchwork has not yet been investigated (Francis and Lorimer 2011). Our results, based on a community approach with a large sample size, indicate that while local factors that are related to habitat structure and complexity, such as the proportion of forbs and bare ground, play an important role for the community composition of most arthropod groups, we did not find that the size of green roofs had an effect on the community. The latter signifies that even small roofs can enhance urban biodiversity if the vegetation structure provides a suitable habitat for different species. The importance of the connectivity variables in explaining the variance of high-mobility roof communities implies movement among roofs, while the spatial clusering (MEM variables) of roof + ground communities, indicates some movement between roof and ground sites. Such an exchange between communities is especially crucial on green roofs since well-connected metacommunities are predicted to be more resilient to stochastic disturbance events and thus have a higher chance of persistence (Fahrig and Merriam 1994). Further, a frequent movement of bees, weevils, and other mobile insects between green roofs and ground sites guarantees the pollination of plants. Reducing meta-community distances by introducing additional green roofs in the landscape will shift the amount of inter-patch dispersal interactions from long-range dispersers towards shorter-range dispersers. Overall, this will increase the effectiveness of short-range pollinating species. There is still a lot of research needed before the relationship between green roof and ground arthropod communities and its effect on plant community is completely understood.

To the best of our knowledge, this is the first study showing that, for many arthropod groups, green roofs are not only a valuable habitat that harbors high arthropod abundance and a large number of species, but that, at least for high-mobility species, they might have the potential to act as stepping stones and to 


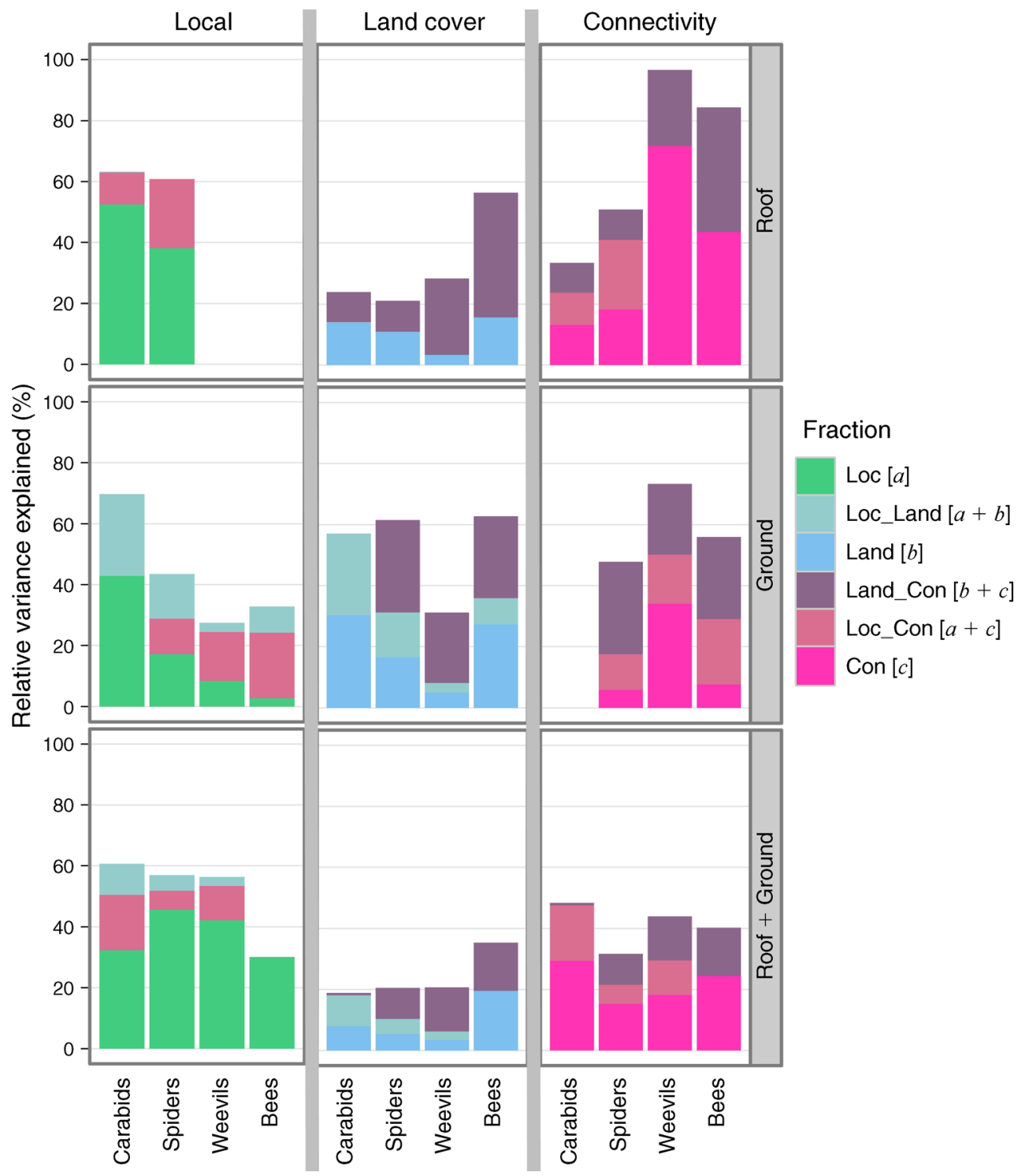

FIG. 3. Variation partitioning of local (Loc), land cover (Land), and connectivity (Con) variables that explain variance in community composition of low- (carabids and spiders) and high- (weevils and bees) mobility arthropod groups (mobility increases from left to right in each panel). From left to right, the proportion of relative variance explained by Loc, Land, and Con, split into pure and joint fractions (Loc_Land represents the joint fraction of local and land cover variables) is shown. Symbols in squared brackets correspond to Fig. 1. The proportions of individual fractions per species group and community analysis (roof, ground, and roof + ground) sum to $100 \%$. This means that for each arthropod group, all corresponding bars per row are the result of the same redundancy analysis (RDA) with variation partitioning analysis. For clarity, the joint fraction of all three environmental sets (Loc_Land_Con) is not represented since it is small and would be equally present in every bar of any analysis.

increase the permeability of the city. It is thus desirable to both improve the design (local variables) of green roofs in order to increase their ecological value, and to integrate green roofs into connectivity concepts of urban planning and management strategies.

\section{ACKNOWLEDGMENTS}

We would like to thank all property owners who gave us access to green roofs and ground sites. For valuable discussions, help with field work, and species determination, we would like to thank F. Bontadina, J. Amacker, F. Fibbioli, U. Kormann (plants), Y. Chittaro (carabids), X. Heer (spiders), C. Germann (weevils), and J. Straka (bees). S. Hose, B. Tschander and K. Hindenlang kindly supported the development of this study. We thank C. Gautschi for the English corrections. The City of Zurich (Gruen Stadt Zurich, GSZ) kindly supported our study. GIS layers were obtained from the Swiss Federal Office of Topography (Vector25 Swisstopo, 2011, DV03594) and from GSZ (Biotoptypenkartierung, 2010). This study was financed by CCES of the ETH Zurich and was part of the project ENHANCE. 


\section{Literature Cited}

Ahrne, K., J. Bengtsson, and T. Elmqvist. 2009. Bumble bees (Bombus spp) along a gradient of increasing urbanization. PLoS ONE 4(5):e5574.

Alberti, M. 2005. The effects of urban patterns on ecosystem function. International Regional Science Review 28:168-192.

Baguette, M., and H. Van Dyck. 2007. Landscape connectivity and animal behavior: functional grain as a key determinant for dispersal. Landscape Ecology 22:1117-1129.

Baranyi, G., S. Saura, J. Podani, and F. Jordan. 2011. Contribution of habitat patches to network connectivity: Redundancy and uniqueness of topological indices. Ecological Indicators 11:1301-1310.

Bates, A. J., J. P. Sadler, A. J. Fairbrass, S. J. Falk, J. D. Hale, and T. J. Matthews. 2011. Changing bee and hoverfly pollinator assemblages along an urban-rural gradient. PLoS ONE 6(8):e23459.

Bell, J. R., D. A. Bohan, E. M. Shaw, and G. S. Weyman. 2005. Ballooning dispersal using silk: world fauna, phylogenies, genetics and models. Bulletin of Entomological Research 95: 69-114.

Berndtsson, J. C. 2010. Green roof performance towards management of runoff water quantity and quality: A review. Ecological Engineering 36:351-360.

Biesmeijer, J. C., and E. J. Slaa. 2004. Information flow and organization of stingless bee foraging. Apidologie 35:143157.

Biotoptypenkartierung der Stadt Zürich. 2010. Gruen Stadt Zürich (GSZ), Zürich, Switzerland. https://www. stadt-zuerich.ch/ted/de/index/gsz/planung_u bau/inventare und_grundlagen/naturschutz-inventar_und_kartierungen. secure.html

Bivand, R. 2011. spdep: Spatial dependence: weighting schemes, statistics and models. http://CRAN.R-project.org/ package=-spdep

Blanchet, F. G., P. Legendre, and D. Borcard. 2008. Forward selection of explanatory variables. Ecology 89:2623-2632.

Borcard, D., F. Gillet, and P. Legendre, editors. 2011. Numerical ecology with R. Springer, New York, New York, USA.

Brenneisen, S. 2006. Space for urban wildlife: Designing green roofs as habitats in Switzerland. Urban Habitats 4:27-36.

Burnham, K. P., and D. R. Anderson. 2002. Model selection and multimodel inference: a practical information-theoretic approach. Second edition. Springer, New York, New York, USA.

Clobert, J., J. F. Le Galliard, J. Cote, S. Meylan, and M Massot. 2009. Informed dispersal, heterogeneity in animal dispersal syndromes and the dynamics of spatially structured populations. Ecology Letters 12:197-209.

Dallimer, M., Z. Y. Tang, P. R. Bibby, P. Brindley, K. J. Gaston, and Z. G. Davies. 2011. Temporal changes in greenspace in a highly urbanized region. Biology Letters 7: 763-766.

Dray, S. 2010. spacemakeR: Spatial modelling. R package version 0.0-5. http://R-Forge.R-project.org/projects/sedar/

Dray, S., P. Legendre, and P. R. Peres-Neto. 2006. Spatial modelling: a comprehensive framework for principal coordinate analysis of neighbour matrices (PCNM). Ecological Modelling 196:483-493.

Duelli, P., M. K. Obrist, and D. R. Schmatz. 1999. Biodiversity evaluation in agricultural landscapes: above-ground insects Agriculture Ecosystems and Environment 74:33-64.

Fahrig, L., and G. Merriam. 1994. Conservation of fragmented populations. Conservation Biology 8:50-59.

Francis, R. A., and J. Lorimer. 2011. Urban reconciliation ecology: The potential of living roofs and walls. Journal of Environmental Management 92:1429-1437.

Francke, W., and K. Dettner. 2005. Chemical signalling in beetles. Pages 85-166 in S. Schulz, editor. Chemistry of pheromones and other semiochemicals II. Springer, Berlin, Germany.

Fuller, R. A., K. N. Irvine, P. Devine-Wright, P. H. Warren, and K. J. Gaston. 2007. Psychological benefits of greenspace increase with biodiversity. Biology Letters 3:390-394.

Gedge, D., and G. Kadas. 2005. Green roofs and biodiversity. Biologist 52:161-169.

Griffith, D. A., and P. R. Peres-Neto. 2006. Spatial modeling in ecology: The flexibility of eigenfunction spatial analyses. Ecology 87:2603-2613.

Grime, J. P. 1977. Evidence for existence of 3 primary strategies in plants and its relevance to ecological and evolutionary theory. American Naturalist 111:1169-1194.

Grimm, N. B., S. H. Faeth, N. E. Golubiewski, C. L. Redman, J. G. Wu, X. M. Bai, and J. M. Briggs. 2008. Global change and the ecology of cities. Science 319:756-760.

Hanski, I., C. Erälahti, M. Kankare, O. Ovaskainen, and H. Siren. 2004. Variation in migration propensity among individuals maintained by landscape structure. Ecology Letters 7:958-966.

Hawkins, B. A., J. A. F. Diniz, L. M. Bini, P. De Marco, and T. M. Blackburn. 2007. Red herrings revisited: spatial autocorrelation and parameter estimation in geographical ecology. Ecography 30:375-384.

Hennig, E. I., and J. Ghazoul. 2011. Plant-pollinator interactions within the urban environment. Perspectives in Plant Ecology, Evolution, and Systematics 13:137-150.

Jackson, H. B., and L. Fahrig. 2012. What size is a biologically relevant landscape? Landscape Ecology 27:929-941.

Legendre, P., D. Borcard, and P. R. Peres-Neto. 2005. Analyzing beta diversity: Partitioning the spatial variation of community composition data. Ecological Monographs 75: 435-450.

Legendre, P., and E. D. Gallagher. 2001. Ecologically meaningful transformations for ordination of species data. Oecologia 129:271-280.

Leibold, M. A. et al. 2004. The metacommunity concept: a framework for multi-scale community ecology. Ecology Letters 7:601-613.

Lindstrom, E. S., and O. Ostman. 2011. The importance of dispersal for bacterial community composition and functioning. PLoS ONE 6(10):e25883.

Logue, J. B., N. Mouquet, H. Peter, H. Hillebrand, and Metacommunity Working Group. 2011. Empirical approaches to metacommunities: a review and comparison with theory. Trends in Ecology and Evolution 26:482-491.

Lundholm, J. T., and P. J. Richardson. 2010. Habitat analogues for reconciliation ecology in urban and industrial environments. Journal of Applied Ecology 47:966-975.

Maurer, U., T. Peschel, and S. Schmitz. 2000. The flora of selected urban land-use types in Berlin and Potsdam with regard to nature conservation in cities. Landscape and Urban Planning 46:209-215.

McGarigal, K., S. A. Cushman, and E. Ene. 2012. FRAGSTATS v4: spatial pattern analysis program for categorical and continuous maps. University of Massachusetts, Amherst, Massachusetts, USA.

McIntyre, N. E., J. Rango, W. F. Fagan, and S. H. Faeth. 2001. Ground arthropod community structure in a heterogeneous urban environment. Landscape and Urban Planning 52:257274.

Oberndorfer, E., J. Lundholm, B. Bass, R. R. Coffman, H. Doshi, N. Dunnett, S. Gaffin, M. Kohler, K. K. Y. Liu, and B. Rowe. 2007. Green roofs as urban ecosystems: Ecological structures, functions, and services. BioScience 57:823-833.

Öckinger, E., A. Dannestam, and H. G. Smith. 2009a. The importance of fragmentation and habitat quality of urban grasslands for butterfly diversity. Landscape and Urban Planning 93:31-37.

Öckinger, E., M. Franzen, M. Rundlöf, and H. G. Smith. 2009b. Mobility-dependent effects on species richness in 
fragmented landscapes. Basic and Applied Ecology 10:573578.

Oksanen, J., F. G. Blanchet, R. Kindt, P. Legendre, P. R. Minchin, R. B. O'Hara, G. L. Simpson, P. Solymos, M. H. H. Stevens, and H. Wagner. 2011. Vegan: community ecology package. http://cran.r-project.org/package=vegan

Olly, L. M., A. J. Bates, J. P. Sadler, and R. Mackay. 2011. An initial experimental assessment of the influence of substrate depth on floral assemblage for extensive green roofs. Urban Forestry and Urban Greening 10:311-316.

Peres-Neto, P. R., P. Legendre, S. Dray, and D. Borcard. 2006. Variation partitioning of species data matrices: Estimation and comparison of fractions. Ecology 87:2614-2625.

Pickett, S. T. A., M. L. Cadenasso, J. M. Grove, C. H. Nilon, R. V. Pouyat, W. C. Zipperer, and R. Costanza. 2001. Urban ecological systems: Linking terrestrial ecological, physical, and socioeconomic components of metropolitan areas. Annual Review of Ecology and Systematics 32:127-157.

R Development Core Team. 2011. R: A language and environment for statistical computing. Reference index version 2.13.0. R Foundation for Statistical Computing, Vienna, Austria. www.r-project.org

Ramalho, C. E., and R. J. Hobbs. 2012. Time for a change: dynamic urban ecology. Trends in Ecology and Evolution 27: 179-188.

Rempel, R. S., D. Kaukinen, and A. P. Carr. 2012. Patch analyst and patch grid. Ontario Ministry of Natural Resources, Centre for Northern Forest Ecosystem Research, Thunder Bay, Ontario, Canada.

Riecken, U., and U. Raths. 1996. Use of radio telemetry for studying dispersal and habitat use of Carabus coriaceus $L$. Annales Zoologici Fennici 33:109-116.

Sattler, T., D. Borcard, R. Arlettaz, F. Bontadina, P. Legendre, M. K. Obrist, and M. Moretti. 2010. Spider, bee, and bird communities in cities are shaped by environmental control and high stochasticity. Ecology 91:3343-3353.

Sattler, T., M. K. Obrist, P. Duelli, and M. Moretti. 2011. Urban arthropod communities: Added value or just a blend of surrounding biodiversity? Landscape and Urban Planning 103:347-361.

Schmid, C. 2004. A new paradigm of urban development for Zurich. Pages 237-246 in R. Paloscia, editor. The contested metropolis: Six cities at the beginning of the 21 st century. Birkhauser, Basel, Switzerland.

Solbreck, C. 1980. Dispersal distances of migrating pine weevils, Hylobius abietis, Coleoptera: Curculionidae. Entomologia Experimentalis et Applicata 28:123-131.

Taylor, P. D., L. Fahrig, K. Henein, and G. Merriam. 1993. Connectivity is a vital element of landscape structure. Oikos 68:571-573.

Thomas, C. D. 2000. Dispersal and extinction in fragmented landscapes. Proceedings of the Royal Society B 267:139-145.
Thomas, J. A., M. G. Morris, and C. Hambler. 1994. Patterns, mechanisms and rates of extinction among invertebrates in the United Kingdom. Philosophical Transactions of the Royal Society B 344:47-54.

Threlfall, C., B. Law, T. Penman, and P. B. Banks. 2011. Ecological processes in urban landscapes: mechanisms influencing the distribution and activity of insectivorous bats. Ecography 34:814-826.

Tonietto, R., J. Fant, J. Ascher, K. Ellis, and D. Larkin. 2011. A comparison of bee communities of Chicago green roofs, parks and prairies. Landscape and Urban Planning 103:102108.

Tratalos, J., R. A. Fuller, P. H. Warren, R. G. Davies, and K. J. Gaston. 2007. Urban form, biodiversity potential and ecosystem services. Landscape and Urban Planning 83:308317.

Tschander, B. 2007. Flachdachbegruenung in der Stadt Zurich. Gruen Stadt Zurich, Naturfoerderung, Fachstelle Naturschutz, Zurich, Switzerland.

Uetz, G. W., J. Halaj, and A. B. Cady. 1999. Guild structure of spiders in major crops. Journal of Arachnology 27:270-280.

United Nations. 2012. World urbanization prospects: the 2011 revision. United Nations, New York, New York, USA.

Urban, M. C. 2004. Disturbance heterogeneity determines freshwater metacommunity structure. Ecology 85:2971-2978.

Van Dyck, H., and M. Baguette. 2005. Dispersal behaviour in fragmented landscapes: Routine or special movements? Basic and Applied Ecology 6:535-545.

Vector25 Swisstopo. 2011. Das digitale Landschaftsmodell der Schweiz. Bundesamt für Landestopographie. http://www. swisstopo.admin.ch/internet/swisstopo/de/home/products/ landscape/vector $25 . \mathrm{html}$

Weller, B., and J. U. Ganzhorn. 2004. Carabid beetle community composition, body size, and fluctuating asymmetry along an urban-rural gradient. Basic and Applied Ecology 5:193-201.

Wesche, K., B. Krause, H. Culmsee, and C. Leuschner. 2012. Fifty years of change in Central European grassland vegetation: Large losses in species richness and animalpollinated plants. Biological Conservation 150:76-85.

With, K. A., R. H. Gardner, and M. G. Turner. 1997. Landscape connectivity and population distributions in heterogeneous environments. Oikos 78:151-169.

Zurbuchen, A., S. Cheesman, J. Klaiber, A. Muller, S. Hein, and S. Dorn. 2010. Long foraging distances impose high costs on offspring production in solitary bees. Journal of Animal Ecology 79:674-681.

Zuur, A. F., E. N. Ieno, N. J. Walker, A. A. Saveliev, and G. M. Smith. 2009. Mixed effects models and extensions in ecology with R. Springer, New York, New York, USA.

\section{Supplemental Material}

\section{Appendix}

Tables showing the number and proportion of species captured on roofs and the ground and the results of the redundancy analysis (RDA) and variation partitioning analyses (Ecological Archives E095-085-A1). 